\title{
A single locus determines thelytokous parthenogenesis of laying honeybee workers (Apis mellifera capensis)
}

\author{
HMG Lattorff ${ }^{1}$, RFA Moritz ${ }^{1}$ and S Fuchs ${ }^{2}$ \\ ${ }^{1}$ Institut für Zoologie, Molekulare Ökologie, Martin-Luther-Universität Halle-Wittenberg, Hoher Weg 4, D-06099 Halle (Saale), \\ Germany; ${ }^{2}$ Institut für Bienenkunde, Universität Frankfurt/M, Karl von Frisch Weg 2, D-61440 Oberursel, Germany
}

\begin{abstract}
The evolution and maintenance of parthenogenetic species are a puzzling issue in evolutionary biology. Although the genetic mechanisms that act to restore diploidy are well studied, the underlying genes that cause the switch from sexual reproduction to parthenogenesis have not been analysed. There are several species that are polymorphic for sexual and parthenogenetic reproduction, which may have a genetic basis. We use the South African honeybee subspecies Apis mellifera capensis to analyse the genetic control of thelytoky (asexual production of female workers). Due to the caste system of honeybees, it is possible to establish classical backcrosses using sexually reproducing queens and drones of both arrhenotokous and thelytokous
\end{abstract}

subspecies, and to score the frequency of parthenogenesis in the resulting workers. We found Mendelian segregation for thelytoky of egg-laying workers, which appears to be controlled by a single major gene $(t h)$. The segregation pattern indicates a recessive allele causing thelytoky. We found no evidence for maternal transmission of bacterial endosymbionts controlling parthenogenesis. Thelytokous parthenogenesis of honeybee workers appears to be a classical qualitative trait, because we did not observe mixed parthenogenesis (amphitoky), which might be expected in the case of multi-locus inheritance.

Heredity (2005) 94, 533-537. doi:10.1038/sj.hdy.6800654

Published online 2 March 2005

Keywords: Apis mellifera capensis; automixis; double backcross; evolution of sex; parthenogenesis; thelytoky

\section{Introduction}

The evolutionary advantage of thelytokous parthenogenesis (asexual production of females) is in producing no males (Maynard Smith, 1978) and thus avoid the 'twofold cost of meiosis' (Williams, 1975). This advantage should result in a spread of a parthenogenetic species compared to a sexually reproducing one, because single individuals can establish new populations. Moreover, parthenogens may have a better ability to establish co-adapted gene complexes (Crow and Kimura, 1965), which are not vulnerable to bottlenecks (Templeton, 1982).

On the other hand, parthenogens suffer from reduced genetic variation, which impedes adaptation to variable environments or changing pathogens (Maynard Smith, 1978; Rice, 1983). Heterozygosity can increase in asexual lineages due to mutational events, but most mutations are deleterious rather than favourable. The lack of recombination can lead to the accumulation of deleterious mutations in the population, a process known as Muller's ratchet (Muller, 1964). Thelytoky is often, therefore, referred to as an evolutionary dead end (Maynard Smith, 1978). Nevertheless, parthenogenetic species may have nearly the same potential to evolve phenotypically as rapidly as related sexually reprodu-

Correspondence: HMG Lattorff, Institut für Zoologie, Molekulare Ökologie, Martin-Luther-Universität Halle-Wittenberg, Hoher Weg 4, D-06099 Halle (Saale), Germany. E-mail: lattorff@zoologie.uni-halle.de Received and accepted 24 January 2005; published online 2 March 2005 cing species (Lynch and Gabriel, 1983). Currently, some 1500 parthenogenic species are known throughout the animal kingdom (White, 1984). However, besides the Bdelloidea (Rotatoria), no higher taxonomic unit consists exclusively of thelytokous species, and the occurrence of thelytokous reproduction appears to be scattered among many taxa, indicating multiple independent phylogenetic origins (White, 1984).

In the social Hymenoptera, only a few cases of thelytokous parthenogenesis are known (Crozier and Pamilo, 1996). Typically, only males are parthenogenetically produced (arrhenotoky) by queens or laying workers and the females are sexually generated diploid offspring. Workers of social insects are usually unable to mate and hence can only lay unfertilised male eggs (Bourke, 1988). Thelytoky has been reported for workers in only a very few species. Four thelytokous ant species are known, Pristomyrmex punctatus (formerly P. pungens), Cerapachys biroi, Cataglyphis cursor and Platythyrea punctata. P. punctatus and C. biroi are obligate thelytokous species, whereas $C$. cursor and P. punctata are facultative thelytokous species (Crozier and Pamilo, 1996). Although thelytokous parthenogenesis is rare in the Western honeybee Apis mellifera (Mackensen, 1943; Tucker, 1958), it is found in egg-laying workers of the Cape honeybee, A. m. capensis (Onions, 1912), although a very low percentage of the workers are arrhenotokous (Hepburn and Crewe, 1991). In this subspecies, nearly all workers are capable of producing female offspring. The cytological mechanism for restoring diploidy is well understood. After a meiotic division, the central haploid 
products fuse to restore the diploid condition, a process known as automixis with central fusion (Verma and Ruttner, 1983). This mechanism does not allow for interchromosomal recombination. Similarly, intrachromosomal recombination (crossing-over) appears to be rare in honeybee worker thelytoky, leading to true clonal offspring. This was first shown by Moritz and Haberl (1994) by analysing worker offspring with multilocus DNA fingerprinting. More recently, a field survey of the population genetic structure of parthenogenetic A. $m$. capensis lineages with microsatellite DNA markers confirmed the clonal reproduction of egg-laying workers with a strongly reduced or zero crossing-over rate (Baudry et al, 2004).

The only published experiments concerning the genetics of the type of parthenogenesis of worker honeybees were conducted by Ruttner (1988). He inseminated endemic $A$. $m$. capensis queens using the semen of a single drone for each. These drones were derived from $\mathrm{F} 1$ hybrid queens of a cross between $A$. $m$. capensis $\times A$. $m$. carnica, representing segregating $\mathrm{F} 2$ gametes. The queens were kept in mating nuclei and, after successful production of worker offspring, the queens were removed to induce egg laying by the workers. The sex of the laying worker offspring in each colony was recorded as the percentage of female to male offspring (see Ruttner, 1988, p 48). The results from 110 queenless nuclei in two successive years show a bimodal distribution from which Ruttner (1988) concluded that thelytokous parthenogenesis is under the control of a single gene. However, $23.6 \%$ of all evaluated queenless nuclei showed intermediate forms of parthenogenesis (amphitoky), which is not expected under the control of a single gene as proposed by Ruttner (1988). Possible reasons for the large proportion of intermediate phenotypes are given by Ruttner himself as (1) a low percentage of thelytokous parthenogenesis $(<1 \%)$ in the European subspecies (Mackensen, 1943) and (2) drifting of workers between the test nuclei, which were not well separated spatially. In addition to these experimental shortcomings, it was not possible to determine the number of reproducing workers per colony. Since Ruttner recorded the proportions of the sexes in the brood derived from multiple egg-laying workers, the brood sex ratios do not allow the scoring of the parthenogenesis type of individual workers. Moreover, conclusions about mixed forms of parthenogenesis (amphitoky) cannot be drawn from the data. Yet, unless the proportion of mixed parthenogenesis (amphitoky) is known, it is not possible to distinguish between singleor multi-locus control of parthenogenesis.

Recently, however, Hoy et al (2003) supposed that cytoplasmatically inherited microorganisms could cause thelytokous parthenogenesis in the Cape honeybee. Indeed, certain Wolbachia strains have been shown to induce parthenogenesis in several parasitic wasps (Stouthamer, 1997; Werren, 1997). Although Wenseleers and Billen (2000) failed to demonstrate the presence of Wolbachia in A. m. capensis, Hoy et al (2003) did detect Wolbachia in this subspecies. Alas, the same Wolbachia strain was also found in arrhenotokous honeybee workers of another subspecies, A. m. scutellata, and so is unlikely to be responsible for thelytoky. Nevertheless, Hoy et al (2003) did not rule out a role for bacteria in inducing thelytoky in Cape honeybees, since other microorganisms have been shown to induce thelytoky (Zchori-Fein et al, 2001; Weeks et al, 2002).

Since Ruttner's (1988) backcross experiments leave ample space for alternative interpretations, we reanalysed a backcross between $A$. $m$. capensis (thelytokous line) and A. m. carnica (arrhenotokous line) under more controlled conditions to evaluate the underlying genetic basis. We used a novel cross type taking advantage of the haplo-diploid system of honeybees. It allows testing for dominant and recessive genes within one test population. We decided to base our analyses on individual worker phenotypes, to overcome the ambiguity of Ruttner's (1988) approach which tested groups of workers.

\section{Material and methods}

\section{Bees and test cross}

We obtained endemic $A$. $m$. capensis queens from the Plant Protection Research Institute (Stellenbosch, South Africa) and performed a test cross as shown in Figure 1. We raised queens from egg-laying worker broods to ensure that potential genes causing thelytoky were included in the cross. All queens were instrumentally inseminated with the semen of $A$. $m$. carnica drones. Queens were raised again from these offspring, representing the F1 generation, which was heterozygous for any thelytoky allele. These heterozygous queens were instrumentally inseminated with the semen of two drones, one $A$. m. capensis (carrying any thelytoky allele) and the other $A$. m. carnica (carrying any arrhenotoky allele). Instrumental insemination followed standard procedures ensuring that the semen of the two drones was evenly distributed. The resulting worker offspring can be considered as a test population, where workers sired by the $A$. m. capensis drone are a backcross to test for recessive factors, whereas the whole population is used to test for dominant and/or maternally inherited factors. As can be easily seen from Figure 1, there is an uninterrupted female transmission line in our cross, so

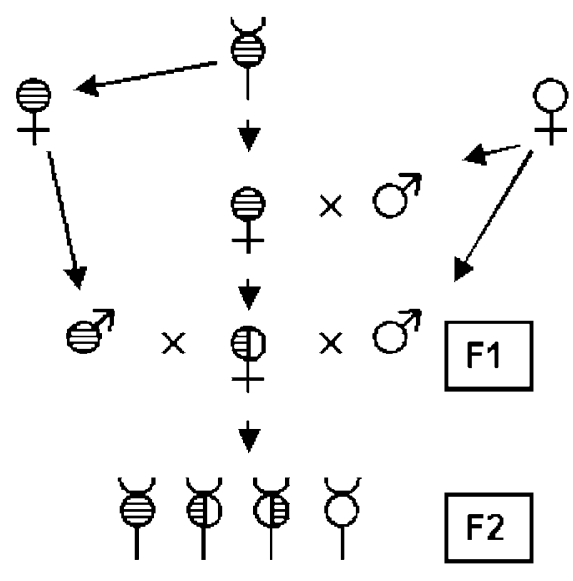

ק thelytokous 0 arrhenotokous

Figure 1 Double backcross of two honeybee subspecies, A. m. capensis and A. m. carnica. For detailed information, see Materials and Methods. 
that maternally inherited factors should show up in the entire tested worker population.

\section{Laboratory assay}

Freshly emerged workers from the test cross were individually marked and introduced into small hoarding cages $\left(10 \times 12 \times 10 \mathrm{~cm}^{3}\right)$ and supplied with a piece of comb $\left(6 \times 5 \mathrm{~cm}^{2}\right)$ and 50 young nursing bees $(A . m$. carnica). Workers of this subspecies are less reproductively dominant, enhancing the chance for egg laying by the tested workers. Food was supplied ad libitum (sugar candy, pollen and water). The cages were kept in a dark room at $33^{\circ} \mathrm{C}$ and a relative humidity of $70-75 \%$. The cages were checked daily for newly laid eggs. Inspections were carried out under red light conditions to keep the bees undisturbed. Eggs were collected and stored at $-20^{\circ} \mathrm{C}$ for later analysis. We used eggs rather then larvae for the analysis of the parthenogenesis type to eliminate any biasing factors including differences in viability of larvae of different sexes. The experiment was terminated after 10 days and all eggs and the marked worker were stored at $-20^{\circ} \mathrm{C}$ until DNA genotyping.

\section{Genotyping}

The egg-laying workers were genotyped at 14 microsatellite loci (A7, A14, A24, A28, A29, A35, A76, A79, A88, A107, A113, AP33, B124, IM; Rowe et al, 1997; Solignac et al, 2003) to determine their paternity. We chose five loci (A29, A35, A88, A113, IM) for which the workers were heterozygous. These loci were used to genotype the eggs laid by the tested workers. Arrhenotokous haploid (hemizygous) and thelytokous diploid eggs (heterozygous) could be easily identified. For each worker, 2-3 eggs were genotyped to independently confirm the ploidy level of the egg.

PCR conditions are used following routine protocols (Rowe et al, 1997; Solignac et al, 2003). Primers were labelled with a fluorescent dye and run on an ABI Prism 310 sequencer. The size of the fragments was calculated using an internal size standard, GeneScan 3.1 and Genotyper 2.0 software (Applied Biosystems).

\section{Results}

\section{Egg-laying workers}

We tested a total of 164 workers, 72 sired by the $A . m$. capensis and 92 by the $A$. m. carnica drone. The number of eggs obtained in the 10-day period ranged from 1 to 23 for individual workers. Significantly more egg layers were offspring of the A.m. capensis drone (31 out of 72), whereas only four out of 92 were of $A$. m. carnica origin.
This reflects the higher reproductive capacity of the $A . m$. capensis drone offspring. We found no evidence for egg laying of the nursing $A$. m. carnica workers that originate from a totally different genetic background.

\section{Genetics of thelytoky}

There was no evidence from our data for a mixed form of parthenogenesis (amphitoky). Workers either exclusively laid female or male eggs. So the form of parthenogenesis is a qualitative and not a quantitative character, which greatly facilitated the further genetic analysis.

For different modes of inheritance (single- and multilocus, complete and incomplete penetrance), the expected segregation ratios can be calculated and compared with the observed segregation pattern. Single-locus models comprise of recessive and dominant as well as maternally inherited genes. Maternal inheritance (eg intracellular transmitted bacteria like Wolbachia) can be treated under the single-locus model, because all their genes are linked and are thus expected to act like a single gene that contributes to the phenotypic effect. A maternally inherited factor (including Wolbachia, etc.) could unambiguously be excluded, because all workers would have been thelytokous, independent of the siring drone. The number of workers and the sex and ploidy of the eggs laid are given in Table 1. This was outside the 0.99 confidence limits of the results for both the $A . m$. carnica and $A$. m. capensis drone offspring, calculated from binomial distributions (Diem and Lentner, 1968). Dominance of thelytoky would result in the typical 1:1 ratio of thelytoky:arrhenotoky in the worker offspring of the $A . m$. carnica drone and, exclusively, thelytokous workers in the $A$. $m$. capensis drone offspring. While this cannot be excluded from the only few reproducing $A$. $m$. carnica drone offspring, exclusive thelytoky is clearly outside the 0.99 confidence limits of the results of the $A$. m. capensis drone offspring. A recessive gene would result in a 1:1 ratio (thelytoky:arrhenotoky) in the workers descending from the $A$. $m$. capensis drone and all other offspring workers of the second drone should be arrhenotokous. The observed segregation within the capensis backcross does not significantly deviate from a 1:1 segregation as expected for a recessive gene $\left(\chi^{2}=0.806, \mathrm{df}=1\right.$, $P=0.369$ ). Furthermore, the expected value of 15.5 falls well within the confidence limits of the observed cases for both thelytoky and arrhenotoky.

Blending the inheritance characteristics of multilocus models would have resulted in amphitokous parthenogenesis, where workers would produce parthenogenetically both female and male offspring in proportions determined by their allelic constitution. No such intermediates were observed.

Table 1 Segregation pattern of parthenogenesis type observed in the testcross

\begin{tabular}{|c|c|c|c|c|c|}
\hline & Total & Nonlaying & Laying & Thelytokous & Arrhenotokous \\
\hline A. m. capensis & 72 & 41 & 31 & $\begin{array}{c}18 \\
10.5-24.7^{*}\end{array}$ & $\begin{array}{c}13 \\
6.3-20.5^{*}\end{array}$ \\
\hline A. m. carnica & 92 & 88 & 4 & $\begin{array}{c}0 \\
0-2.4^{*}\end{array}$ & $\begin{array}{c}4 \\
1.6-4^{*}\end{array}$ \\
\hline
\end{tabular}

A. $m$. capensis and A. m. carnica denote the fathering drone of the workers.

*0.99 confidence limits. 
Recombination and form of parthenogenesis

All marker loci used are unlinked and located on different chromosomes (Solignac et al, 2003). Therefore, we cannot give any data on the frequency of recombination in arrhenotokous workers. The diploid eggs produced by the thelytokous workers do allow a recombination analysis. Only four recombination events were detected in the entire sample over all loci (three at locus A29 and one at locus A88). As loci became homozygous in these cases, the data should be treated with great care, since we cannot separate misamplification, recombination and mutation.

\section{Discussion}

Our results suggest that the type of parthenogenesis in laying honeybee workers is a qualitative character determined by a single major locus, which we term thelytoky $(t h)$. Our results support the conclusions of Ruttner (1988), who first proposed that thelytoky is caused by a single recessive gene. Genetic control by means of multiple loci is not consistent with the absence of intermediate parthenogenesis types (amphitoky). It could be argued that we did not detect amphitokous individuals due to a sampling error collecting three eggs of the same ploidy state just by chance alone. We tested this scenario by calculating the probability from a multinominal distribution for the distribution we obtained, assuming different proportions of amphimictic individuals. The result of 18 strictly thelytokous and 17 arrhenotokous individuals is best explained by the lack of any amphimictic individuals $(P=0.134)$.

We cannot completely exclude the possibility that the mode of parthenogenesis is under multi-locus control, which does not result in blending inheritance. However, this would require very specific and complex interactions with partial dominance and/or partial epistasis among the genes involved. Thus, although we cannot exclude complex genetic control, we follow 'Ockham's razor' in preferring the single-locus model.

The hypothesis of parthenogenesis inducing bacteria as proposed by Hoy et al (2003) can clearly be rejected. These cytoplasmatically inherited bacteria (eg Wolbachia) cause different phenotypes including cytoplasmic incompatibility, male killing and induction of parthenogenesis (for a review, see Werren, 1997). Parthenogenesis induction is just described for a few species (eg Trichogramma spec.) of the Hymenopteran taxa Chalcidoidea and Cynipoidea (Stouthamer, 1997). Wolbachia interferes with meiosis and causes gamete duplication after meiosis to restore diploidy. This mechanism leads to complete homozygosity of the whole genome. However, the two Hymenopteran superfamilies in which gamete duplication occurs have no single locus complementary sex determination (sl-CSD) common to most other Hymenopterans (females are heterozygous for the sex locus). In species with sl-CSD, like the honeybee, gamete duplication would lead to the production of diploid sterile males, which should be opposed by strong selection (Cook, 1993). Although other bacteria may be able to induce parthenogenesis (Zchori-Fein et al, 2001; Weeks et al, 2002) using other mechanisms than gamete duplication, our study clearly shows that there is no maternally inherited factor causing thelytoky in the Cape honeybee.
The genetics of thelytoky has also been studied in Plathythyrea puncata (Schilder et al, 1999a,b). This Ponerine ant species shows different modes of reproduction. Queens and gamergates (= mated workers) reproduce sexually or through arrhenotoky, whereas unmated workers can exhibit thelytokous parthenogenesis. There is a high intraspecific variation for the type of reproduction (Heinze and Hölldobler, 1995; Schilder et al, 1999a).

Two nuclear genes causing thelytoky have been found in Drosophila melanogaster (Fuyama, 1986). In contrast to the workers of the Cape honeybee, these fruit fly females of the strain gyn-F9 need to mate to receive sperm that activates the eggs without contributing genetic material (gynogenesis). Despite this difference, this is the only other case where single genes could be identified, which cause thelytoky.

Species which show intraspecific variation of parthenogenesis with arrhenotokous and thelytokous forms cannot interbreed to produce segregating populations, because the thelytokous females will not mate with males or produce triploid offspring. One exception may be the endoparasitic wasp Venturia canescens. Schneider et al (2003) detected gene flow between arrhenotokous and thelytokous populations in the laboratory. It could be shown that there is a genetic basis for the thelytoky in $V$. canescens ( $\mathrm{Li}$ et al, 2003).

The Cape honeybee seems to be an excellent model system to further study the genetics and evolution of thelytoky. The reproductive division of labour between queens and egg-laying workers leads to a decoupling of sexual and thelytokous production of females. Male haploidy allows the production of double backcrosses from one queen, as presented in this paper. The recent development of 550 microsatellite markers (Solignac et al, 2003) as well as the ongoing efforts in sequencing the honeybee genome will greatly facilitate the identification and location of the gene responsible and the mechanisms underlying the thelytoky phenotype in honeybee workers.

\section{Acknowledgements}

We thank B Springer (Institut für Bienenkunde, Oberursel) for instrumental insemination of the queens. We also thank $\mathrm{MH}$ Allsopp for providing the $A$. m. capensis bees. $\mathrm{P}$ Neumann and $\mathrm{S}$ Härtel provided useful comments on an earlier version of the manuscript. This work was financially supported by grants from the Volkswagenstiftung and the DFG to RFAM.

\section{References}

Baudry E, Kryger P, Allsopp MH, Koeniger N, Vautrin D, Mougel $\mathrm{F}$ et al (2004). Whole-genome scan in thelytokous laying workers of the Cape honeybee (Apis mellifera capensis): central fusion, reduced recombination rates, and centromere mapping using half-tetrad analysis. Genetics 167: 243-252.

Bourke AFG (1988). Worker reproduction in the higher eusocial Hymenoptera. Quart Rev Biol 63: 291-311.

Cook JM (1993). Sex determination in the Hymenoptera: a review of models and evidence. Heredity 71: 421-435.

Crow JF, Kimura M (1965). Evolution in sexual and asexual populations. Am Nat 99: 439-450.

Crozier RH, Pamilo P (1996). Evolution of Social Insect Colonies. Oxford University Press: Oxford. 
Diem K, Lentner C (1968). Wissenschaftliche Tabellen, 7th edn. J.R. Geigy A.G., Pharma: Basel.

Fuyama Y (1986). Genetics of parthenogenesis in Drosophila melanogaster. II. Characterization of a gynogenetically reproducing strain. Genetics 114: 495-509.

Heinze J, Hölldobler B (1995). Thelytokous parthenogenesis and dominance hierarchies in the ponerine ant, Platythyrea punctata (F. Smith). Naturwissenschaften 82: 40-41.

Hepburn HR, Crewe RM (1991). Portrait of the Cape honeybee, Apis mellifera capensis. Apidologie 22: 567-580.

Hoy MA, Jeyaprakash A, Alavarez JM, Allsopp MH (2003). Wolbachia is present in Apis mellifera capensis, A. m. scutellata, and their hybrid in Southern Africa. Apidologie 34: 53-60.

Li D, Zhao Z, Roberts H, Schneider MV, Theopold U, Schmidt O (2003). Genetic analysis of two distinct reproductive strategies in sexual and asexual field populations of an endoparasitic wasp, Venturia canescens. Heredity 90: 291-297.

Lynch M, Gabriel W (1983). Phenotypic evolution and parthenogenesis. Am Nat 122: 745-764.

Mackensen O (1943). The occurrence of parthenogenetic females in some strains of honeybees. I Econ Entomol 36: 465-467.

Maynard Smith J (1978). Evolution of Sex. Cambridge University Press: Cambridge.

Moritz RFA, Haberl M (1994). Lack of meiotic recombination in thelytokous parthenogenesis of laying workers of Apis mellifera capensis (the Cape honeybee). Heredity 73: 98-102.

Muller HJ (1964). The relation of recombination to mutational advance. Mutat Res 1: 2-9.

Onions GW (1912). South African 'fertile-worker bees'. S Afr Agric J 1: 720-728.

Rice WR (1983). Parent-offspring pathogen transmission: a selective agent promoting sexual reproduction. Am Nat 121: 187-203.

Rowe DJ, Rinderer TE, Stelzer JA, Oldroyd BP, Crozier RH (1997). Seven polymorphic microsatellite loci in honeybees (Apis mellifera). Insectes Soc 44: 85-93.

Ruttner F (1988). Taxonomy and Biogeography of Honeybees. Springer: Berlin.

Schilder K, Heinze I, Gross R, Hölldobler B (1999a). Microsatellites reveal clonal structure of populations of the thelytokous ant Platythyrea punctata (F. Smith) (Hymenoptera; Formicidae). Mol Ecol 8: 1497-1507.

Schilder K, Heinze J, Hölldobler B (1999b). Colony structure and reproduction in the thelytokous parthenogenetic ant Platythyrea punctata (F. Smith) (Hymenoptera, Formicidae). Insectes Soc 46: 150-158.

Schneider MV, Driessen G, Beukeboom LW, Boll R, van Eunen $\mathrm{K}$, Selzner A et al (2003). Gene flow between arrhenotokous and thelytokous populations of Venturia canescens (Hymenoptera). Heredity 90: 260-267.

Solignac M, Vautrin D, Loiseau A, Mougel F, Baudry E, Estoup A et al (2003). Five hundred and fifty microsatellite markers for the study of the honeybee (Apis mellifera L.) genome. Mol Ecol Notes 3: 307-311.

Stouthamer R (1997). Wolbachia-induced parthenogenesis. In $\mathrm{O}^{\prime}$ Neill SL, Hoffmann AA, Werren JH (eds) Influential Passengers - Inherited Micro-organisms and Arthropod Reproduction. Oxford University Press: Oxford. pp 102-124.

Templeton AR (1982). The prophecies of parthenogenesis. In: Dingle H, Hegmann JP (eds) Evolution and Genetics of Life Histories. Springer: New York. pp 75-101.

Tucker KW (1958). Automictic parthenogenesis in the honeybee. Genetics 43: 299-316.

Verma S, Ruttner F (1983). Cytological analysis of the thelytokous parthenogenesis in the Cape honeybee (Apis mellifera capensis Escholtz). Apidologie 14: 41-57.

Weeks AR, Marec F, Breeuwer JAJ (2002). A mite species that consists entirely of haploid females. Science 292: 2479-2482.

Wenseleers T, Billen J (2000). No evidence for Wolbachia-induced parthenogenesis in the social Hymenoptera. J Evol Biol 13 277-280.

Werren JH (1997). Biology of Wolbachia. Annu Rev Entomol 42 : 587-609.

White MJD (1984). Chromosomal mechanisms in animal reproduction. Bull Zool 51: 1-23.

Williams GC (1975). Sex and Evolution. Princeton University Press: Princeton.

Zchori-Fein E, Gottlieb Y, Kelly SE, Brown JK, Wilson JM, Karr TL et al (2001). A newly discovered bacterium associated with parthenogenesis and a change in host selection behavior in parasitoid wasps. Proc Natl Acad Sci USA 98: 12555-12560. 